\title{
Where Everybody Knows Your Name: Lessons in Innovation from the High-Tech Sector
}

\author{
Stephen Burdon, Grant Mooney and Kyeong Kang \\ University of Technology Sydney, Australia
}

Correspondence should be addressed to: Grant Mooney; Grant.Mooney@uts.edu.au

Received date: 29 September 2017; Accepted date: 3 January 2018;

Published date: 10 October 2018

Academic Editor: Nor Azlina Ab.Rahman

Copyright (C) 2018. Stephen Burdon, Grant Mooney and Kyeong Kang . Distributed under Creative Commons CC-BY 4.0

\begin{abstract}
This paper examines the major priorities and prevailing values of firms highly regarded for innovation success within the Australian high-tech sector. In conjunction with the Information Industry Association of Australia (AIIA), a survey was undertaken regarding member perceptions of peer enterprises most admired for innovation origination and delivery. 244 responses from 102 organisations were received, analysed and compared. Direct follow-up with selected enterprises then more closely examined factors deemed key to sustaining a cycle of innovation leadership. Findings suggest that firms most esteemed by peers also prioritise the realisation of innovation over simply making money - yet both high growth and cash flows are still habitually generated.Results also show that having a strong reputation for innovation is a competitive advantage in its own right as they attract invitation to cross-enterprise ecosystems and beneficial partner alliances. Interestingly however, topics linked to outsider/peer perceptions of rival enterprises seem to collect comparatively limited precedence within innovation debates. What our study shows is that balancing an internal reality of innovation with the external perception for innovation can lead firms to significant improvements in overall commercial performance.
\end{abstract}

Keywords: Reputation; innovation; organisation growth, high-tech.

\section{Introduction}

Innovation continuously redefines markets and opens up new sectors of economic and social activity. Nowhere is this more obvious than in hi-tech digital sector where competition is extremely high and Moore's Law (and the onus to introduce new product innovations every 18 to 20 months) has been the central and continuing precept since the 1950's. With delivery cycles shortening in a globally

Cite this Article as: Stephen Burdon, Grant Mooney and Kyeong Kang (2018)," Where Everybody Knows Your Name: Lessons in Innovation from the High-Tech Sector", Journal of Innovation \& Business Best Practice, Vol. 2018 (2018), Article ID 592653, DOI: 10.5171/2018.592653 
pervasive survival-of-the-fittest business environment it could be argued that technology firms have simply been a vanguard for imperatives that other industries now find themselves increasingly and more overtly sharing. In fact, researchers Al-Hawari and Hasan (2002, p88) state this more explicitly: "globalization, created by the new IT has placed businesses everywhere in a new and different competitive situation".

This paper explores innovation drivers and attributes from the peer/competitor perspectives of multiple technology organisations. In particular it starts with three hypotheses for examination:

1. Innovation output and high levels of corporate growth are linked;

2. Innovation delivery is more prevalent in smaller firms than larger ones;

3. Sustaining innovation requires a culture of collaboration and competitive awareness.

Using a targeted survey across the membership of a technology-focused industry body we assessed responses from 244 respondents across 102 organisations, seeking to identify a sub-set of innovation characteristics that superior organisations (per collective peer nomination and annual revenue increase) seem to share. The intent was to better understand the real priorities exemplar firms' exhibit in competing in a sector premised upon market change, multiple rivals and the acute need for tangible (and fast) delivery of innovative outcomes.

\section{Literature Review}

Pursuit of innovation has been repeatedly identified as a major cornerstone of successful firms. For example, a relatively recent study by market research firm AON Hewitt (2011) investigated over 180 international organisations and reported the consistently superior financial performance of companies receiving high scores both internally (employees) and externally (competitors) in regard to innovation culture and behaviours. These organisations averaged 38\% higher return on investment and $22 \%$ higher gross margin than other market counterparts. Similarly, the work by Jaruzelski et al. (2011) suggests businesses with cultures highly aligned to innovation can post up to $30 \%$ higher growth in enterprise value than rivals. These authors are not alone as over the last decade many researchers (e.g. Christensen \& Raynor (2003); Piperopoulos \& Scase (2009); Vaccaro et al. (2010); Borjession \& Lofsten (2012); Szczygielski et al. (2017)) have found themselves independently repeating the same litany linking innovation and corporate growth.

Organisational attitude to economic context is relevant as to whether innovation-based growth might emerge. In a series of papers, Ron Adner (e.g., Adner (2002); Adner \& Zemsky (2005)) discussed the introduction of innovation suggesting it as a product of changes in consumer demand coupled to an ability and desire for firms to respond appropriately. Another researcher, Rebecca Henderson (2006), later supported this view by promoting innovation as an outcome of market-facing competence. In other words, aligning an organisation towards innovation-based imperatives requires not only continuously upgrading internal enterprise capabilities but also developing a 360 degree strategic awareness of what others are doing in the same market space. It compels organisations to step beyond rhetoric to decisively resolve whether they are truly willing to compete. Such resolutions are especially difficult for some (mainly large) firms that may have to restructure and/or cannibalise existing product lines - ones potentially still earning revenue - in order to meet emerging market shifts and keep ahead of smaller rivals with less legacy but more hunger. Clayton Christensen, one of the acknowledged experts on management and innovation growth, suggests that "corporate executives often bet the future of billion-dollar enterprises on an innovation" (Christensen \& Raynor (2003, p.7)). Understanding market forces, and the positioning and capabilities of rivals also contending within those markets, becomes a strong corollary to innovation 
efforts and whether such billion-dollar hopes are well founded.

Leaders within the business sector well appreciate the value of proactively gathering market intelligence and assessing the actions and capabilities of rivals. Lönnqvist \& Pirttimäki (2006, p.32) suggest "the need for timely and effective business information is recognized as essential for organizations not only to succeed, but even to survive" while Nallari et al. (2011, p.162) assert that "efforts to promote competitiveness through innovation can rarely be understood in isolation from what others are achieving". This awareness also has a long-standing tradition within academic literature going back to Michael Porter (1990) and his writings around the four conditions for business competitiveness:

1. Factor conditions (i.e. skilled labour and infrastructure)

2. Demand conditions

3. Supporting industries (including competitive suppliers)

4. Enterprise rivalry

In light of the current topicality of innovation and its recurring mention as an enterprise competitive strategy, it is interesting to note that three of Porter's four points acknowledge the importance of linking competitive behaviours to an outward-facing perspective. Conversely however, contemporary academic additions regarding innovation seem to primarily focus upon inward-facing enterprise viewpoints - that is, Porter's point one. Reviewing examples of literature in the innovation space shows a preponderance of discussion around enablement via internal frameworks, updating business models, increasing staff knowledge, improving enterprise culture and so on:

- Pearce et al. (2009) suggest that to sustain innovative competitiveness organisations leverage individual talent and disciplined internal teamwork;

- Manz et al. (2009, p.180) advocate a fluid self-determination which allows "followers to become leaders and participate in the management process" as a way to prompt innovative outcomes;

- Chesbrough \& Appleyard (2007) promote the use of internal teambased practices towards innovating with more open mindsets;

- Hamel (2009) advocates capitalising on employee passion in enacting innovation;

- Talukder \& Quazi (2010) argue that employees must accept innovation to reap its benefits so attention to the process of individual engagement and acceptance is crucial.

To the lesser extent where external engagement is considered, and while awareness is growing, it is often in the sense of building co-creation efforts with immediate customers or integrating elements of the enterprise supply chain activities generally aligning with Porter's points two and three:

- Blumentritt (2004, p.29) identifies "discovery of new ways to establish and maintain relationships with customers as one of the key tenets for promoting innovation in enterprise";

- Di Gangi et al. (2010) recommend customers as integral to innovation process;

- Grissemann and Stokburger-Sauer (2012) test a co-creation model within the travel industry;

- Burdon et al. (2015) discuss the benefits of integrating innovation co-creation into engineering services;

- Voorburg et al. (2015) argue for cocreation with citizens as necessary for creating innovative public sector services;

- Chapman \& Corso (2005) examine collaborative innovation within elements of an extended manufacturing enterprise.

Without diminishing in any way the value such contributions and other similarly excellent writings provide, innovation researches intersecting Porter's point four 
(and consideration of how rivalry can influence innovation emergence) seem to earn relatively less air-time. Also, while not quite a gap, much of the extant literature linking innovation, competitiveness and competitive perspective appears increasingly dated.

Firms in similar industries are a group whose perceptions matter. A reputation for innovation with market peers can influence corporate choice in regard to constructing supply chains, inter-organisational collaboration, forming of joint ventures and so on. In fact, business trends suggest that the nature of commercial competition is evolving away from individual company rivalry towards one of contending alliances - a reality where "firms take part in endproduct supply networks that compete against alternative end-product networks" (Chapman \& Corso (2005, p.339)). For such a paradigm, organisations seen by others as exemplifying innovation have a distinct advantage in being able to attract complementary relationships with industry associates, partners, customers and past rivals towards bonding strong future coalitions.

In particular, the growing trend to 'coopertition' (a neologism coined to describe cooperative competition) and establishing limited but mutually beneficial alliances with previous adversaries seems under-represented in the innovation discussion. Tether (2002, p.950) noted the value of maintaining competitive awareness when he investigated 2342 firms regarding innovation efforts and concluded that "while suppliers and customers were the most widely engaged co-operation partners...significant proportions also engaged competitors" and that "these links may be associated with the development of more significant, higher level innovations". Cleff et al. (2005, p.138) agree, suggesting from their study of the automotive industry within the European Union, that "if companies decide to cooperate they consider every potential partner...it is striking that competitors are often used as collaboration partners". This again affirms the intense links needed for the development of complex products.
This thought may also have implications attached to size of firm. Researchers, such as Foster and Kaplan (2001), claim that innovation has at least three different genres - incremental, radical and transformational - with the emergence of the latter two (radical and transformational) arguably aligning with Cleff et al.'s comment about 'complex products'. In fact, Tether (2002, p.965) makes this link explicit: "developing higher level (i.e. more radical or complex) innovations were more likely to have cooperative arrangements for innovation with external partners". However, there is ardent debate when it comes to whether larger or smaller firms are better at enacting such practices. For example, Clark \& Guy (1998, p.372) agree that while "leader companies showed a stronger external orientation" that typically "it is larger firms which have the stronger links"; Tang (2006, p.78) supports this point saying "large firms are more likely to introduce an innovation output...than small firms". Challenging these views as somewhat distorted, Gronum et al. (2012, p.258) suggest that "the bulk of the research on the impact of both innovation and networks on performance has been undertaken in large firms" but that consideration of other evidence shows overwhelming correlation between innovation and SME performance: "firms that are both small and already established are significant drivers of economic growth". Similarly, Remneland-Wikham (2011, p.725) state that radical and transformational innovation categories posit the need for new behaviours and "learning of a new modus operandi...coupled with a vast amount of unlearning of past modus operandi" activities that may be less straightforward for larger entities with historical investment in current processes.

A further reason of the need for competitive awareness is supplied by Tang (2006, p.70) where he asserts "that prudent managers are more likely to maintain higher levels of perception about the degree of competition and to undertake innovation efforts". The suggestion is that 
an organisation may deliberately leverage innovation investment towards copying the strengths and/or targeting tactical weaknesses of rivals if the enterprise keeps such knowledge current and is poised to act. In fact, two of Tang's conclusions from studying enterprise behaviours are that market arrival of competing products positively correlates to intensified innovation product $\mathrm{R} \& \mathrm{D}$, while rapid changes in technologies provide a spur to process innovation activities. Awareness of competition creates an environment where firms feel pressure to develop and renew in order to keep their sector standing.

While reasons may be quite multifaceted (e.g. trading know-how, enhancing acceptance of an innovation, increasing resource/competency pools, mutual challenge of an incumbent, market reach, etc.), the concept of 'today's competitor, tomorrow's collaborator' is a precept of growing significance and especially where markets are fast changing and/or the risk from failure is high. Thus, maintaining an outward-facing attentiveness to competitive activity - and being able to internally organise to reap best advantage from that through enterprise networking or enterprise contending - is a spur to innovative outcomes and acquiring and sustaining a market leadership position.

Christensen in various publications (Christensen (1997); Christensen (2003); Dyer et al. (2011)) often discusses the transformational effect of emergent technologies terming these as 'disruptive innovation' for very good reasons. Developing (and sustaining) significant innovation is a complex issue, closely tied not only to idea generation but also delivery within a commercial setting - and willingness for organisations to adjust their perceptions not just their profit margins. Greco et al. (2016) point out that orchestration of successful innovation collaboration can be as challenging as it is potentially rewarding so selection of channel partners must be informed. One thing is likely from what we already know: attempting an end-run at innovation by simply boosting funding within a moribund schema absent market intelligence isn't directly correlated to either progress or profit. However, it does raise a question: for firms seeking growth via innovation activity then, from the watchful perspective of peers, where do the best of these firms place emphasis towards achieving their innovation goals? The possibilities for an organisation owning both an external reputation for innovation excellence and an internal ability to execute strategy appear significant.

\section{Research Methodology}

Research was undertaken with the
Australian Association (AIIA). The information industry was chosen because of its heavy reliance upon continual improvement and as a high-tech sector known as a longstanding source of innovation. Two recent investigations reinforce this point: McKinsey\&Company found that while most organisations were concentrating upon core products in the post global financial crisis aftermath, information service and tech based firms differed by actively attempting "to grow through opportunities adjacent to our core business" (Capozzi et al. (2010, p.1); also Gottlieb \& Willmott (2014, p.2) conclude from their recent work that in pursuing new business "digitization has become a critical asset in many companies quest for growth". Further support in direct relation to innovation emergence is provided by Cleff et al. (2005, p.139) where, in summarising their EU study, they state that "long-term factors lay the foundation for the respective innovation system and its development and have to be linked to opportunities arising due to information and communication technologies" and that " $90 \%$ of all future innovation ...will be driven by IT” (2005, p.146).

The AIIA database comprises a community of nearly 600 information-provider and information-served organisations. Of this number, non-profit, academic, governmentfunded and similar entities were excluded from the study with the remaining 405 commercial enterprises forming the initial research subset. Many firms within the study actively compete with one another. 
The initial research approach was quantitative in nature. A questionnaire employing a six-point Likert scale (i.e. strongly disagree, disagree, slightly disagree, slightly agree, agree, strongly agree) was administered across ten selected topics derived from earlier research by the authors into innovation culture and frameworks. The areas included:

1. Vision, goals and strategic plan/intent

2. Integration of innovation into the business

3. Aligning staff to strategic innovation

4. Building of innovation networks

5. Selecting/provisioning of projects

6. Rewarding ideas and delivery

7. Adaption to change

8. Building community culture to drive innovation

9. Regard/orientation to action and risk-taking

10. Promoting of staff capability and improvement

Questions were posed to management and employees within target organisations with voluntary participation encouraged via their AIIA membership. The survey was administered by neutral third party with close attention given to preserving individual anonymity. Demographic data were also gathered to better understand type, size and growth of respondent business. Data coding and analysis was enabled using statistical software. The survey received 244 responses from 102 organisations.

Considering our first two hypotheses, namely:

- Innovation delivery and high levels of corporate growth are linked;

- Innovation delivery is more prevalent in smaller firms than larger ones.

Research data were initially analysed by organisation growth (increasing profit over recent financial periods) versus reputation for innovation delivery; and by organisation size (previous-year revenue) versus reputation for innovation delivery. The employing of annual financial growth as a proxy for commercial success aligns to findings in both academic and commercial literature. For example, Birley \& Westhead (2006) endorse growth in profitability or number of employees as acceptable scales for measuring corporate success. Similarly, AON Hewitt (2011) in a comparative piece of market research nominated success as the growing of gross margins, return on investment and profit.

The final part of the survey asked participants to recommend up to three rival organisations they perceived as exemplars of innovation, provide specific reasons for such recommendation and a subjective comparison of their own enterprise against these same factors. The validity of perception-based metrics when assessing competitive situations is endorsed by Tang (2005, p70) who suggests that "the degree of firm-specific competition may not be correctly measured using traditional statistics" but that employing "the perception-based measure reflects not only competition from domestic markets but also competition from overseas". This section of enquiry was more open as firms nominated did not have to be members of AIIA, could be associated with any sector owning a strong technical capability (i.e. not just technology but also finance, engineering, defense, medical, etc.) and respondents were able to answer in their own words at some length. Nominee organisations were grouped by size: small firms up to $\$ 2$ million turnover; medium firms over $\$ 2$ million to $\$ 50$ million turnover; large firms over $\$ 50$ million turnover. It should be noted that while 'large' firms linked to high-production economies may be diversely classified, for Australian-based information technology organisations within the AIIA membership database a $\$ 50+$ million annual revenue is considered respectable. A fourth category was reserved for innovative multinational organisations.

Firms perceived as best-of-breed in each category by industry peers were independently approached for discussion regarding their enabling of innovation and governance attributes ascribed to its successful delivery. A transcript series was 
created from the recorded dialogues as addendum data supporting the original study. Data coding and subsequent analysis allowed archetype attributes to be more closely profiled towards addressing hypothesis 3:

- Sustaining of innovation requires a culture of collaboration and competitive awareness

Moving from broader quantitative aspects to a more focused qualitative examination within nominated businesses was enlightening as well as allowing crosscorrelation of common themes.

\section{Findings from the Study}

\section{How Innovative are Organisations when Segmented by Growth?}

There appears a strong link between ability to deliver innovation and significant financial growth.

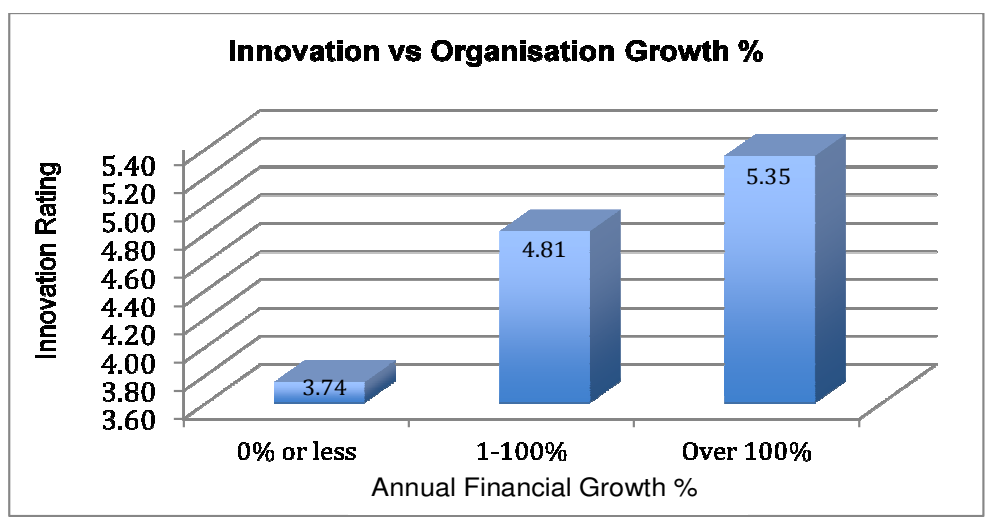

Figure 1: Innovation realization compared to percentage annual growth

Supporting research hypothesis 1, companies rated highest by sector peers for their capability to develop and sustain innovative outcomes (5.35) also regularly posted more (some much more) than $100 \%$ growth per annum. Conversely, companies showing impairment in ability to generate innovation (3.74) also experienced flat or negative growth compared to rivals.
More light can be shed on these results by analysing views of executive respondents, especially their top three reasons for overtly admiring sector contemporaries (and nominating them as innovation exemplars) and in then examining their own enterprises' internally espoused priorities. While there was some minor variation in positioning, eight areas were seen to be common foci for innovation exemplar enterprises in the high-growth category.

Table 1: Business priorities for leader (innovative high-growth) organisations

\begin{tabular}{|l|c|}
\hline Priority Area & Rank \\
\hline Development of great ideas & $\mathbf{1}$ \\
\hline Execution and implementation of ideas & $\mathbf{2}$ \\
\hline Able to engage talent to innovate & $\mathbf{3}$ \\
\hline Practiced at taking risks & 4 \\
\hline Decisive in making choices & 5 \\
\hline $\begin{array}{l}\text { Organisational growth (capability, market, } \\
\text { revenue) }\end{array}$ & 6 \\
\hline Proactive organisation culture & 7 \\
\hline Long term in their decisions & 8 \\
\hline
\end{tabular}

Stephen Burdon, Grant Mooney and Kyeong Kang (2018), Journal of Innovation \& Business Best Practice, DOI: $10.5171 / 2018.592653$ 
Firms able to repeatedly innovate seemingly encourage enterprise-wide behaviours to stimulate ideas backed by practices to execute those ideas well - and they build ecosystems for marshaling talent internally and across enterprise boundaries. Such engagements, while situational, are neither abstract nor symbolic but are expected to produce realistic results. As one major aerospace/defense representative stated, the goal was to achieve "innovation with a purpose"; an IT respondent suggested that to create something distinctive "you need pragmatism" for delivery. Achieving a working balance between innovation input and innovation output was highly valued.

Also, while the top three items in Table 1 stood well above, the remaining attributes clearly supported them. Risk acceptance (4) and decisiveness (5) referenced clarity of leadership in charting a short/mediumterm path and harmonising operational investment to speedy outcomes; proactive culture (7) highlighted the presence of a 'can do' organisational attitude surrounding innovation elements; long term thinking/decision making (8) promoted planning and channel-building required for future innovation cycles. Interestingly, growth as a focus item was somewhat down the list at sixth place and tended to be assessed more descriptively as 'organisational growth' using a scorecard of measures of which revenue was just one component.

Compare these to ranking of business priorities given by surveyed executives referencing their own firms shown in Table 2. Perhaps unsurprisingly, a more procedural range of foci were evident.

Table 2: Business priorities for typical organisations

\begin{tabular}{|l|c|}
\hline Priority Area & Rank \\
\hline Revenue growth & $\mathbf{1}$ \\
\hline Customer relationships & $\mathbf{2}$ \\
\hline $\begin{array}{l}\text { Product improvement (incremental } \\
\text { innovation) }\end{array}$ & $\mathbf{3}$ \\
\hline Solution delivery (incremental innovation) & 4 \\
\hline Use of technology & 5 \\
\hline Operational efficiency & 6 \\
\hline Employee skills acquisition/recruitment & 7 \\
\hline Speed to market & 8 \\
\hline
\end{tabular}

Most respondent organisations were typically seen to prioritise revenue generation, cost containment and local improvements linked to these. Innovation as an organisational focus was more lowkey and often regarded as tactical supplement for other objectives.

The analysis strongly suggested two findings. First, companies where innovation is strategically esteemed tend to be among the more successful within their sectors. Second, for the majority of these firms, corporate growth presents more as an outcome of other-goal achievement rather than a goal in/of itself. Such organisations are ambitious in ways extending beyond simply making money.

\section{How Innovative are Organisations when Segmented by Size (Turnover)?}

As seen in Figure 2, small to mid-sized firms hold a general perception of being more innovative places to work (ratings of 5.16 and 5.18 respectively). 


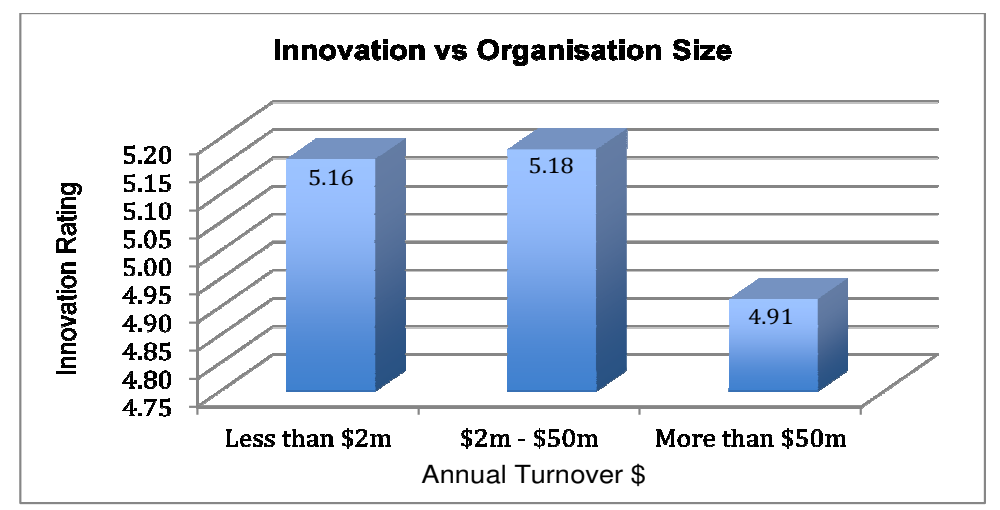

Figure 2: Innovation realisation compared to organisation size (annual \$ turnover)

This also supports commercial research from Katzenbach et al. (2014) where they suggest that shaping an innovation culture (or any culture) is much easier to do when an enterprise is starting out small. Reinforcing this, responses within the survey alluded to smaller firms assertively leveraging creative relationships as a source of competitive advantage. One respondent, in reference to his organisation departing from market norms to develop innovative software, simply highlighted the degree of pride they take in their brand and of how their "teams want to create excellence".

Mid-level companies apparently took a more balanced view of risk/reward selectively choosing ideas and then, once committed, proactively managing proposals through to profitable realisation. To "solve people problems...not technical problems" in identifying and agilely meeting a market need - an outward-facing focus on accomplishment rather than pure revenue generation.

In contrast, large organisations tended to rate least for innovation delivery (4.91), often seen as instituting process filters and risk management overhead to guard against investment failure and/or damage to existing assets. In illustration, one senior manager described executive decisionmakers examining a particular idea, assessing its risk profile and then "decided it had no future". This same intellectual property, judged too risky by its original organisation, is now the basis for a worldleading cryptographic technology experiencing phenomenal international recognition and generating very high levels of revenue for its new owners.

The outcomes superficially support hypothesis 2 in that small/medium sized firms were seen as more innovative than those in the large category when assessed by market peers. The data also refute other research promoting larger companies as better positioned to deliver advancement (Tether (2002); Tang (2006)). Pertinent, however, are two further pieces of information from our study.

First, examining the ownership structures of the organisations it was noted that partnerships/joint ventures and private firms fared best in innovation delivery while publicly-listed entities fared worst. 


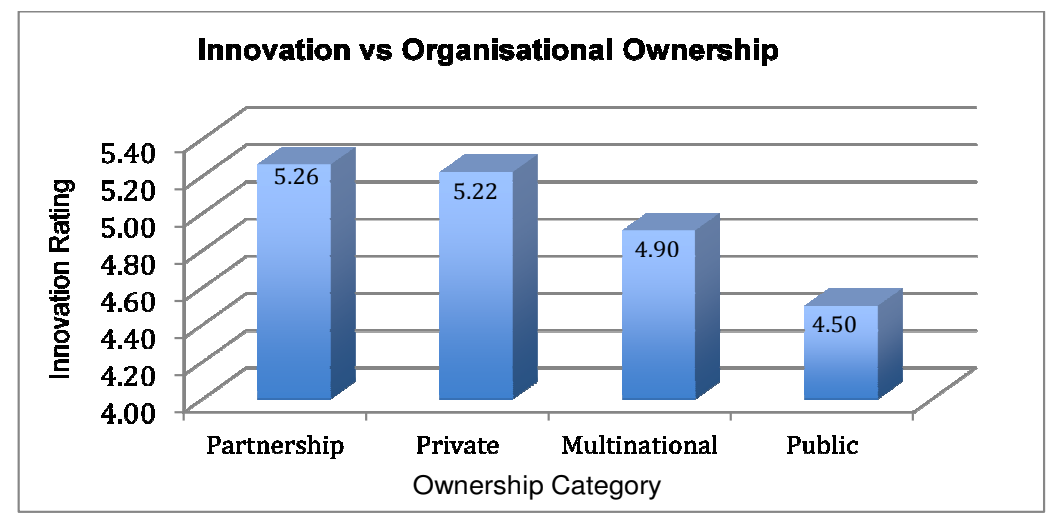

Figure 3: Innovation realisation compared to organisation ownership

As partnerships and private firms in the study were generally much smaller than publically-listed counterparts, these datasets appeared to correlate. Second, grouping by these categories and looking deeper into specific responses across the ten areas investigated (see Methodology) it was clear that the smaller private companies repeatedly outstripped larger firms in three innovation rating areas:

- Building innovation networks (5.16 versus 4.92);

- Adaption to change (5.31 versus 4.84);

- Building community culture to drive innovation efforts $(5.22$ versus 4.73 ).

This suggests that size of organisation wasn't the only determining factor but rather the ability to quickly adapt while building competitive innovation networks/communities inter- and intraorganisationally. It just so happens that, within the Australian context at least, many enterprises leveraging networks to create innovation capability also happened to be small-to-medium in scale.

\section{How do Peers Self-Rate Compared to Exemplar Organisations?}

The most innovative organisations nominated by respondents were Quintessencelabs (small firms up to $\$ 2$ million turnover), Xero (medium firms up to $\$ 50$ million turnover) and Atlassian (large firms over $\$ 50$ million turnover). Google was seen as the most innovative multinational organisation (and most admired for innovation overall) with Apple not far behind. While many respondents regarded their own firms as somewhat innovative in selected areas, these five companies clearly stood out as innovation exemplars across the surveyed categories. Intriguingly, the enterprises all competed as digital technology product/service providers - prompting a closer examination of responses for this sub-sector across the ten innovation topic areas included in the survey methodology.

Omitting organisations responding but outside the targeted band (e.g. consultancies, finance firms, media, managed service/infrastructure providers, commercial/scientific R\&D, airlines, etc.) 65 digital-provider companies remained. Averages in rank order for these firms across the analysis areas are summarised in Figure 4. 


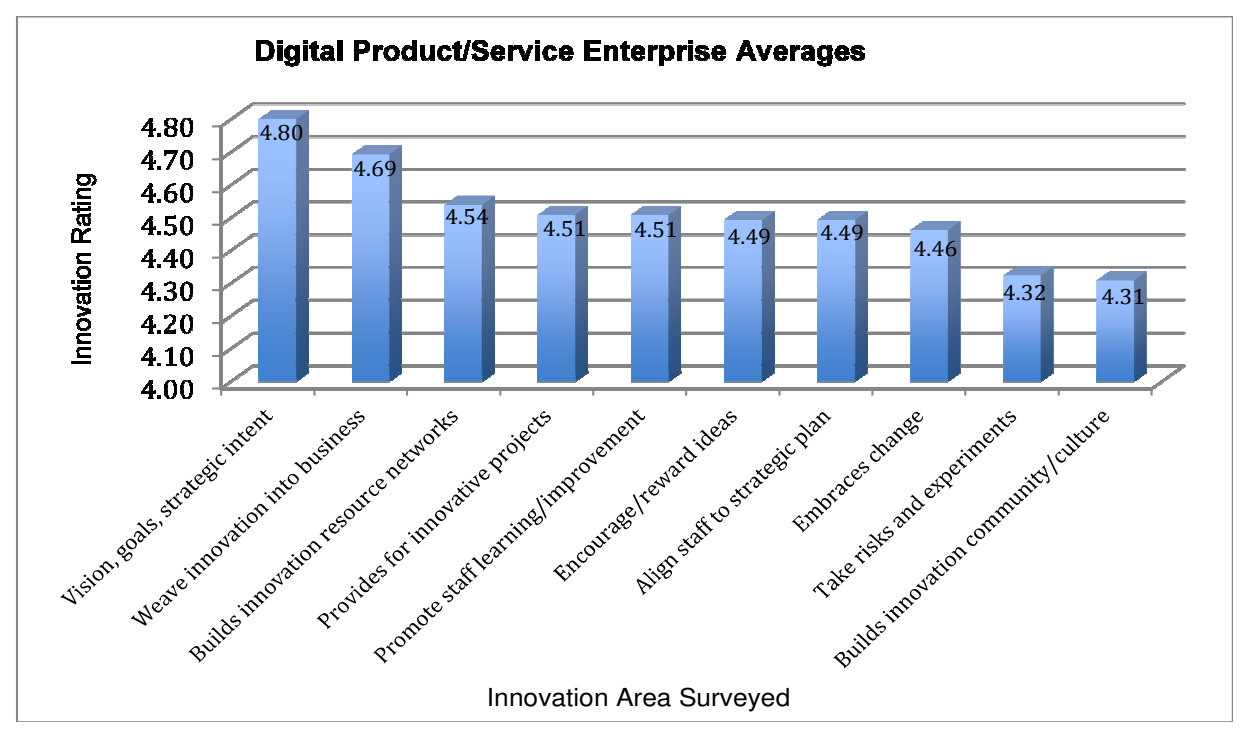

Figure 4: Innovation area mean for companies competing with exemplar organisations

While exemplar firms had peer ratings approaching near maximum of 6.0 across survey areas, most sector competitors selfrated much less. This was particularly evident around the lower average scores given to considerations of community (4.31) and openness to risk-taking and experimentation (4.32) provided by a number of firms in the sub-group. Exhibiting a strong 'not made here' ambivalence for outside ties, these often chose to aim innovation effort toward reinforcing a management vision (4.80) and aligning operational process and staff education in support - generally, internally focused activities. While most digitaldriven organisations in the analysis were noted as profitable, per capita revenues for those with a primarily inward-facing ethos varied well below the growth bands of the exemplars against whom they were directly setting themselves.

Linking back to Table 1, firms that sustain high levels of innovation/growth also value collaborative development, pro-action and engagement of talent. This supports hypothesis 3 in that the best-of-class seemed to actively follow a more open paradigm, freely seeking collaboration and engagement with both internal and external stakeholders. Via communities-ofpractice, cultural alignments and desirable alliances they sought to extend networks, market reach and competitive advantage while spiritedly branding themselves as attractive partners for innovation cocreation initiatives.

\section{Discussion}

Achieving innovation clearly fosters significant levels of revenue income for organisations that can produce them. Percentage annual growth levels, at least for best-in-class companies, can easily reach triple digits for a finite span of time. Further, correlations between the response data summarised in Figures 1 and 2 indicate such heights most often occur in companies valued at less than $\$ 50$ million the small-to-medium end of the size scale.

What is intriguing is where strategic focus is directed between those who achieve high growth and those that only achieve incremental levels. High-innovation organisations deliberately build networks of capability and then engage aspirations of those in this network to collectively create outcomes. Coupling talent to pro-action as 'top-10' activities (Table 1) they develop innovation ecosystems leveraging cultural practice to minimise process, abbreviate decision cycles and cut time for activities to complete. In contrast, low-innovation organisations rely more on directed compliance to management-quantifiable goals... and with time-consuming approvalchains to verify this. While pockets of 
innovation can (and indeed do) exist in less spirited firms, the development of an innovation ecosystem as a unifying principle often seems to miscarry when affixed to short-term corporate imperatives and self-protective bureaucracies. In these cases, while incremental improvements may be very achievable, market perspectives seem to place the more radical game-changing outcomes as beyond easy reach.

The key thought we discover from the current investigation is the importance to innovative outcomes of hosting an extended ecosystem beyond organisational boundaries. Stepping beyond simply increasing resources, this commitment becomes a shared philosophy encompassing like-minded organisational entities as an interlinked value system. We can see this in the first three exemplar priorities identified in Table 1 development of great ideas, execution and implementation of ideas and able to engage talent actively extend into co-creation with outside entities and the collective building of reach, value, network alliances and sustainable growth. Tang (2006, p81) suggests that 'small firms are as efficient as large firms in converting innovation input into innovation output' but lack their inputcreating capacities. In proactively building community units comparable to large organisations smaller innovative firms surmount such impediments. This incidentally renders hypothesis 2 (and whether large or small organisations are best at producing innovation) largely moot. While acknowledging the value of hosting broad capabilities, innovation appears less a question of organisational scale alone and more a consequence of successfully enacting a well-informed competitive strategy.

Intriguingly, there was another aspect pertaining to the question of growth. While standard organisations seek growth they most often limit it to considerations of revenue. Indeed, in sampling comments from the study this theme was very much in evidence: one senior respondent from a large multinational summed their company's approach to innovation simply as "profitability"; another stated they were about "scaling business [income] through leveraging intellectual property"; a third aimed at "recurring revenue above 95\%"; while a fourth mentioned "any change you make, anything you do cannot harm...our bread and butter". Thus, they explicitly restricted development to pathways that did not disturb existing income streams. In contrast, exemplar organisations had a much wider definition of growth, judging not just in terms of revenue but also capability and market presence. As respondent of one of these latter firms stated their mission is "to actually change the world". Dissatisfied with incremental improvement and bypassing nostalgia for established product lines these firms don't just compete they assertively compete: engaging, experimenting, networking, risk taking and moving forward rapidly. This outcome endorses conclusions by Kishna et al. (2016, p276) in that "dissatisfaction with current system functioning is the main trigger of discontinuous innovation", plus a Prahalad \& Ramaswarmy (2004) finding of the need to build 'innovating experience environments' across a wide front as a way to engage competitively. Our research supports a case for companies contending at transformational levels proactively pursuing alliances with quality partners (including previous competitors) to deliberately disrupt the existing status quo, rather than to just make money.

Yet, despite the lower immediate concern given to revenue, firms known to embody innovation enabling elements (as per Table 1) can rapidly become dominant in their markets. Google and Apple are two such illustrations. Likewise, in the Asia-Pacific finance sector Commonwealth Bank has long held clear strategic intent towards innovation, rating particularly well as a respondent nominee within the Table 1 exemplar areas of development of great ideas, execution and implementation of ideas and being able to engage talent to innovate. Perhaps not coincidentally, recent business press (Maiden (2014)) names Commonwealth Bank as the top retail bank in Australia, holding best return on equity of $18.7 \%$ while exhibiting a $62 \%$ increase in share price since 2007, thus putting 
them at nearly twice the value growth of their next closest rival. Examples such as these help clarify the principal relationship between innovation and income as being success at the former sustaining growth of the latter - but without the converse necessarily holding true.

\section{Conclusion}

All three of our starting hypotheses were found to be supported but with intriguing insights attached.

First was the clear finding that a perception for radical progress among marketplace peers/consumers is very beneficial to attaining a market leadership position. This is especially significant for smaller and medium sized organisations pursuing an innovation agenda. Sector standing can act as a filter for identifying potential innovation partners, encourage complementary organisations into association and allow resulting collectives to successfully compete against larger rivals - whereas operating individually they may simply not have the commercial leverage or entrepreneurial capability to challenge established positions. This outward-facing radar seems to be a common aspect of best-of-breed organisations seeking to produce the next disruptive innovation. Brand management and awareness are important and an organisation's market power appears, in turn, strongly influenced by its industry marque and reputation for innovation.

This is an area apt for further research. While much has been written around internal cultural requisites for innovation, comparatively less is available on how a positive reputation as a source of innovation contributes to ongoing marketplace success. What can be demonstrated from our study is that a high external score from competitors coupled with a high internal score from employees is a strong indicator that an organisation is, indeed, a leading institution in its field. Firms might find it interesting to survey their respective industries regarding the general perception of their own innovation capability.
Second, somewhat unexpectedly, was a realisation that highly innovative firms often don't focus primarily on profit. Instead, they look to innovation as a means of making their organisations distinct. A corollary to the branding and marketfacing awareness mentioned previously, they emphasise building of an enabling culture, developing desired capabilities and constructing progression cycles where originality can emerge. Revenue generation is a managed consequence of having such cycles complete successfully. Conversely, behaviours that inhibit innovation cycles are regarded as also inhibiting business growth (a proxy for organisation success) and thus obstacles to be confronted quickly and removed with extreme prejudice. Prizing differentiation, adaption and high levels of autonomy these organisations live the business adage: “Don't reward success and punish failure; instead reward success, reward failure and punish inaction". Income is the bounty for getting the balance right.

Third, while this current research suggests smaller organisations as more innovative the best of them can - and do - emulate the reach of larger entities by forming active alliances and enduring partnership networks. Therefore, claiming a causal link between innovation output and size of organisation is somewhat simplistic. Instead, emergence appears more a question of organisational attitude and building prerequisites for an interlinked innovation ecosystem - including short decision cycles, talent collaboration, engaged culture, energy, minimised institutional structures, low process overheads and so on - irrespective of enterprise scale. While such characteristics are most commonly associated with small/medium firms, larger corporations like Google, Apple and Commonwealth Bank clearly have no problem producing novel outcomes. However, it is worth noting that these three do purposefully what others may do by happenstance namely, flattening management layers, investing in a proactive ethos and choosing high degrees of inter-organisational networking as part of their operational models. They could also be regarded as 
mega-corporations posting annual turnover results numbered in billions of dollars... significantly above the $\$ 50$ million mark the researchers used as a high-water threshold in this current study. This posits an additional intriguing area for future research. Exploring entities of megacorporation size may provide interesting insights into innovation emergence where views of risk, resource provision and constraint limitation are arguably atypical compared to most organisations responding to our current study. For megacorporations, the market power they wield and greater resource pool offered by subsidiaries may be sufficient to generate innovations without the same need to draw on outside agencies.

We hope that the insights contained in this paper will help organisations to better appreciate organisational perspectives and benefits attached to sustaining innovation especially when operating within a highly fluid marketplace.

\section{Acknowledgements}

The authors would like to express their gratitude to the AIIA and member organisations for their candor in contributing to our research and to the external reviewers for helpful comments on early versions of this paper.

\section{References}

1. Adner, R. (2002) 'When are technologies disruptive: a demand based view of the emergence of competition', Strategic Management Journal, 24(10), 1011-1027.

2. Adner, R. \& Zemsky, P. (2005) 'Disruptive technologies and the emergence of competition', RAND Journal of Economics, 36(2), 229-254.

3. Al-Hawari, M. \& Hasan, H. (2002) 'Evaluating the knowledge assests of innovative companies', Australasian Journal of Information Systems, 10(1), 88-98.

4. AON Hewitt (2011) Trends in Gobal Employee Engagement, AON Hewitt Ltd, London.

5. Birley, S. \& Westhead, P. (2006) 'Growth and performance contrasts between 'types' of small firms', Strategic Management Journal, 11(7), 535-557.

6. Blumentritt, T. (2004) 'Does small and mature have to mean dull? Defying the hohum at SMEs', Journal of Business Strategy, 25(1), 27-33.

7. Borjesson, S. \& Lofsten, H. (2012) 'Capabilities for innovation in small firms a study of 131 high-tech firms and their relation to performance', International Journal of Business Innovation and Research, 6(2), 149-176.

8. Burdon, S., Mooney, G. \& Al-Kilidar, H. (2015) 'Navigating service sector innovation using co-creation partnerships', Journal of Service Therory and Practice, 25(3), 285-202.

9. Capozzi, M, Gregg, B \& Howe, A. (2010) 'Innovation and commercialisation 2010', McKinsey Global Survey Results, McKinsey\&Company, 1-5.

10.Chapman, R.L. \& Corso, M. (2005) 'From continuous improvement to collaborative innovation: The next challenge in supply chain management', Production Planning and Control, 16(4), 339-344.

11. Chesbrough, H. W. \& Appleyard M.M. (2007) 'Open innovation and strategy', California Management Review, 50(1), 5776.

12.Christensen, C. (1997) The Innovator's Dilemma, Harvard Business School Publishing, Boston.

13.Christensen, C. (2003) 'Six keys to building new markets by unleashing disruptive innovation', E-Partner HBSWK, March 10, 1-6.

14.Christensen, C. \& Raynor, M. (2003) The Innovator's Solution, Harvard Business School Publishing, Boston.

15.Clark, J. \& Guy, K. (1998) 'Innovation and competitiveness: A review', Technology Management and Strategic Management, 10(3), 363-395.

16.Cleff, T., Licht, G., Spielkamp, A. \& Urban, W. (2005) Europe's automotive industry on the move: Competitiveness in a changing world, Eurpoean Centre for Economic Studies (Heneric, O., Licht, G. and Softka, W. eds.), Mannheim, Germany.

17.Di Gangi, P.M., Wasko, M. \& Hooker, R. (2010) 'Getting customers' ideas to work for you - learning from Dell how to succeed with online user innovation communities', MIS Quarterly Executive, 9(4), 213-228. 
18.Dyer, J.H., Gregersen, H.B. \& Christensen, C.M. (2011) The Innovator's DNA: mastering the five skills of disruptive innovators, Harvard Business School Press, Boston.

19.Foster, R. \& Kaplan, S. (2001) Creative Destruction, Doubleday Publishing, New York.

20.Gottlieb, J. \& Willmott, P. (2014) 'The digital tipping point', McKinsey Global Survey Results, McKinsey\&Company, NJ.

21.Greco, M., Grimaldi, M. \& Cricelli, L. (2016) 'An analysis of the open innovation effect on firm performance', European Management Journal, 34(5), 501-316.

22.Grissemann, U. \& Stokburger-Sauer, N. (2012) 'Customer co-creation of travel services: The role of company support and customer satisfaction with the co-creation performance', Tourism Management, 33(6), 1483-1492.

23.Gronum, S., Verreynne, M. \& Kastelle, T. (2012) 'The role of networks in small and medium-sized enterprise innovation and firm performance', Journal of Small Business Management, 50(2), 257-282.

24. Hamel, G. (2009) 'Moon Shots for Management', Harvard Business Review, 87(2), 91-98.

25.Henderson, R. (2006) 'The innovator's dilemma as a problem of organizational competence', Product Innovation Management, 23, 5-11.

26.Jaruzelski, B., Loehr J. \& Holman, R. (2011) 'Global innovation 1000: why culture is key', Strategy + Business, Booz \& Co., 65, [Online], [Accessed 3 January 2018], $\quad$ http://www.strategybusiness.com/article/11404

27.Katzenbach, J., von Post, R. \& Thomas, J. (2014) 'The critical few: components of a truly effective culture', Strategy+Business, Spring, 74, 1-9.

28.Kishna, M., Negro, S., Alkemade, F. \& Hekkert, M. (2017) 'Innovation at the end of the life cycle: discontinuous innovation strategies by incumbents', Industry and Innovation, 24(3), 263-279.

29.Lönnqvist, A. \& Pirttimäki, V. (2006)

'The measurement of business intelligence', Information Systems Management, 23(1), 32-40, [Online], [accessed 3 January 2018], http://dx.doi.org/10.1201/1078.1058053 0/45769.23.1.20061201/91770.4
30. Maiden, M. (2014) 'Gail Kelly's legacy: positive and growing', Sydney Morning Herald, November 14, [Online], [accessed 3 January 2018], http://www.smh.com.au/business/comme nt-and-analysis/gail-kellys-legacy-positiveand-growing-20141114-11mydw.html

31.Manz, C.C., Pearce, C.L. \& Sims Jr, H.P. (2009) 'The ins and outs of leading teams: An overview', Organizational Dynamics, 38(3), 179-182.

32. Nallari, R., Yusuf, S., Griffith, B. \& Bhattacharya, R. (2011) Frontiers in Development Policy: A Primer on Emerging Issues, The World Bank, Washington DC. 33.Pearce, C.L., Manz, C.C. \& Sims Jr, H.P. (2009) 'Where do we go from here?: Is shared leadership the key to team success?', Organizational Dynamics, 38(3), 234-238.

34.Piperopoulos, P. \& Scase, R. (2009) 'Competitiveness of small and medium sized enterprises: Towards a two dimensiohnal model of innovation and business clusters', International Journal of Business Innovation and Research, 3(5), 479-499.

35.Porter, M. (1990) The Competitive Advantage of Nations, Macmillan, New York.

36.Prahalad, C.K. \& Ramaswamy, V. (2004) The Future of Competition: Co-Creating Unique Value with Customers, Harvard Business Press Books, Boston.

37. Remneland-Wikhamn, B. (2011) 'Path dependence as a barrier for 'Soft' and 'Open' innovation', International Journal of Business Innovation and Research, 5(6), 714-730.

38.Szczygielski, K., Grabowski, W. \&

Woodward, R. (2017) 'Innovation and the growth of service companies: the variety of firm activities and industry effects',

Industry and Innovation, 24(3), 249-262.

39.Talukder, M. \& Quazi, A. (2010) 'Exploring the factors affecting employees' adoption and use of innovation', Australiasian Journal of Information Systems, 16(2).

40.Tang, J. (2005) 'Competition and innovation behaviour', Research Policy, 35(1), 68-82.

41.Tether, B. (2002) 'Who co-operates for innovation, and why: an empirical analysis', Research Policy, 31(6), 947-967. 
42.Vaccaro, A., Parente, R. \& Veloso, F. M. (2010) 'Knowledge management tools, inter-organizational relationships, innovation and firm performance', Technological Forecasting \& Social Change, 77(7), 1076-1089.
43.Voorburg, W., Bekkers, V. \& Tummers, L. (2015) 'A systematic review of co-creation and co-production: embarking on the social innovation journey', Public Management Review, 17(9), 1333-1357. 